\title{
COVID-19 PANDEMIC: A SERIOUS THREAT FOR PUBLIC MENTAL HEALTH GLOBALLY
}

\author{
Samiaa Anjum ${ }^{1}$, Rooh Ullah ${ }^{2}$, Muhammad Suleman Rana ${ }^{3}$, Hamid Ali Khan $^{4}$, Fawad Shabir Memon ${ }^{5}$, \\ Yasin Ahmed $^{1}$, Sadia Jabeen ${ }^{6}$ \& Rani Faryal ${ }^{1}$ \\ ${ }^{1}$ Department of Microbiology, Quaid-i-Azam University, Islamabad, Pakistan \\ ${ }^{2}$ Department of Microbiology, Sarhad University of Science and Information Technology, Peshawar, Pakistan \\ ${ }^{3}$ Department of Virology, National Institute of Health, Islamabad, Pakistan \\ ${ }^{4}$ Institute of Biological Sciences, Sarhad University of Science and Information Technology, Peshawar, Pakistan \\ ${ }^{5}$ Institute of Microbiology, University of Sindh, Jamshoro Sindh, Pakistan \\ ${ }^{6}$ Department of Microbiology, Harbin Medical University, Harbin, China
}

received: 4.5.2020;

revised: 15.5.2020;

accepted: 22.5 .2020

\section{SUMMARY}

Deep emotion traumas in societies around the globe are overcome by extreme human catastrophes such as natural disasters, social crises, war conflicts and infectious virus induced pandemic diseases, etc., can lead to enormous stress-related disorders. The current ongoing pandemic known as COVID-19 caused by novel Corona virus first appeared in Wuhan, city of China and then rapidly spread in the whole world. It has affected various frontiers of lives and caused numerous psychiatric problems like nervousness, post-traumatic stress disorder (PTSD), fear and uncertainty, panic attacks, depression, obsessive compulsory disorder, xenophobia and racism, etc. Globally COVID-19 has persuaded public mental health crisis. Furthermore, inadequate resources of public mental health services in several countries are discussed in this review, which will be further straighten by the upcoming increase in demand for mental health services due to the COVID-19 pandemic. All mental health sciences including Psychiatry can play a very important role in the comfort of COVID-19 infected individuals and their relatives, healthcare providers and society. We need to learn more about psychological and psychiatric features of COVID-19 from the perceptions of public and global mental health in order to cope up the present deteriorating situation caused by the SARS-CoV-2 pandemic.

Key words: COVID-19 pandemic - global health crisis - mental health - SARS-CoV-2

$$
* * * * *
$$

\section{INTRODUCTION}

A new strain of Corona virus appeared in the start of 2020 in Wuhan, China which causes acute respiratory syndromes and thus, quickly spreads all over the world (Ahmed et al. 2020, Wang et al. 2020). The case fatality rate (CFR) of COVID-19 is $7.07 \%$ which is greater than that of influenza and it is more contagious when compared to other severe acute respiratory syndrome (SARS) (Bouey 2020, Yang et al. 2020). It has affected more than 210 countries worldwide up till April 30th, with an approximately 3,189,594 active cases and an astonishing death rate of 225,755 globally (WHO 2020). At the time of influenza outbreak (HINI) in the past in 1918-19 which was also declared as global pandemic, the death ratio reached 50 to 100 million (Johnson \& Mueller 2002), including numerous cases of mental health problems (Young 2016).

At present, as no appropriate treatment is available for the disease, many countries around the globe are responding COVID-19 via different strategies involving combination of mitigation and quarantine (Anderson et al. 2020, Parodi \& Liu 2020) with the objective of deferring major flow of patients and steamrolling the demands of hospital admissions while safeguarding the most vulnerable from infection like the elderly and pa- tients with comorbidities (Bedford 2020). On the other side, this method has created an impending sense of fear as the psychosocial life of the public has been disrupted and leads to provoking several mental issues like anxiety and depression. Moreover, while many developed countries like USA and Italy have the resources to deal with social and financial crises, it is still difficult for them to overcome such issues. In the developing countries like Pakistan, where majority of population consist of labors and daily wages with low income are also facing the same problem with full impact of the pandemic and complete or partial lockdown within the country leads to anger, depression, frustration and many other psychological problems (Ahmad et al. 2020).

The current ongoing pandemic of COVID-19 has raised several questions about the value and the role of mental health sciences and psychiatry in the field of medicine. Transdisciplinary integrative-psychiatry has been playing three different roles: 1. to study, identify, find a treatment and preventive measures for mental disorders; 2 . to help other medicinal branches to encourage person-centered medicine with practicing the consultation-liaison psychiatry; and 3. to endorse the importance of mental health among the public and the concept of empathic civilization and compassionate society (Jakovljevic 2017, 2018). 


\section{MENTAL HEALTH AND PANDEMICS}

Several researchers have identified that there is a direct link between chronic diseases like tuberculosis and immunodeficiency virus (HIV) with mental disorders like depression in general public (van den Heuvel et al. 2013, Gale et al. 2018, Kuan et al. 2019). Similarly, various studies were designed during and after Ebola epidemics in 2014 and SARS in 2003, revealed that fear inducing over reactive behavior among the general population has also been observed (Person et al. 2004, Shultz et al. 2016). Additionally, various psychiatric problems like depression, nervousness and posttraumatic stress complaint has been found specifically in healthcare workers and in survivors (Gardner \& Moallef 2015, Blakey et al. 2019).

\section{Psychological impact of COVID-19 on mental health}

Confirmed COVID-19 pandemic is attributed to the global scale severity of the present public health problems which effected above 210 countries globally. Currently, the full level of economic and social consequences can't be predicted but can be understand from the facts that many countries globally have executed full or partial lockdowns (Cosic et al. 2020). While the critically important issues such as containment of virus, treatment of patients and progress of vaccine development are being addressed, it is also necessary to address the prolonged effects of de-stabilized mental health globally. Due to outlined economic reasons and public health, it is crystal clear that COVID-19 causes a serious threat to mental health globally. For instance, a WHO guideline stated that "increased rates of stress and anxiety is the main psychological impact of the pandemic up till now", with a warning that "as new measures especially quarantine are introduced, its impact on public's daily activates, livelihoods, loneliness levels, harmful drugs and alcohol use, depression, and suicidal behavior or selfharm are also expected to rise" (WHO 2020).

\section{Aggression, anxiety, frustration and post-traumatic stress disorder}

When a pandemic appeared in the world, initially the public response to it consists of immense fear and uncertainty that the likely physical and mental health outcomes of the virus pandemic can be less or more predicted and will most probably include: dropped perceived health; negative social activities caused by anxiety and disrupted perception of risks including distress reactions like anger, fear, insomnia and health risk behaviors such as high consumption of tobacco and alcohol and social isolation, along with mental health diseases (anxiety, PTSD and depression etc) (Shigemura et al. 2020). Patients having definite and suspected COVID-19 and those who are quarantined will more likely to suffer from frustration, loneliness and anger if compared to previous outbreaks like SARS (Xiang 2020).

To illustrate the ongoing effect of COVID-19 on mental health, a study was conducted in china included 2091 citizens and it was observed that one month after the outbreak, in mainland China the prevalence of PTSD was $4.6 \%$ while high prevalence of PTSD (18.4\%) was recorded among the high risk public such as those living in Chinese provinces which have the highest figure of COVID-19 positive cases (Sun et al. 2020). Similarly, mental health care professionals and survivors suffering from PTSD is also of great concern. Another study was conducted in a Beijing hospital where health workers and medical professionals who worked at high risky sites such as SARS unit were quarantined reported significantly increased level of PTSD, and other mental conditions such as fear, frustration, depression and anxiety compared to those without same practices (Wu et al. 2009, Kaiser 2020, Yi et al. 2020). Also, in a country like Pakistan where uncertainty is not only because of the pandemic but most of the population is also uncertain about their disturbed work life and next meal due to lockdown, mental troubles such as frustration and aggression will be common. Comparably, health workers who are working in quarantine centers with lack of PPEs and the death of their related personals can lead to numerous PTSD symptoms. Thus, therapies like stressadaptation model should be applied by mental health professionals to lower the stress level among health care workers (Hamza Shuja et al. 2020).

\section{COVID-19 and obsessive-compulsive disorder (OCD)}

Contamination obsession is a continuous unwanted discomfort associated with one's cleanliness and a person have a constant urge for washing or sterilizing and such condition is usually classified as obsessive compulsive disorder (Williams et al. 2013). This form of OCD can increase panic attacks leads to disturbance and operative impairment of the patient in case of an infectious virus generated pandemics. Such condition needs to be monitored carefully and regularly as nations like Pakistan where only elite class visited the mental health professionals and majority of the population are not registered to mental health professionals and thus suffer significantly in such situation. Clinical Psychologists should try to resolve such mental issues with great care among the general public, by giving more attention towards such impending issues (Hamza Shuja et al. 2020). Nowadays, different scientists are conducting various studies to analyze the effect of COVID-19 virus pandemic on mental health indicating that to minimize the mental health damage by the Corona virus, timely actions must need to be undertaken by the governments and health officials (Cosic et al. 2020). 


\section{MENTAL HEALTH ISSUES AMONG CASES, HEALTH PROFESSIONALS AND GENERAL PUBLIC DURING COVID-19 PANDEMIC}

Physical suffering aside, immense psychological burden and other health associated problems are common among suspected or confirm COVID-19 individuals. Fear of severe disease outcomes and the contagion might be experienced by these individuals (Xiang et al. 2020). As a result, mental problems like loneliness, anxiety, denial, insomnia, despair and depression are experienced by the confirmed or suspected cases which leads to lower treatment adherence. Some of these individuals may also experience high risk of anger and suicide. Due to the doubt about their health status, suspected isolated individuals may suffer from fear and anxiety and thus develop obsessive compulsory disorder symptoms which include repeated hand wash, checking temperature again and again and follow other prevention procedure persistently. Furthermore, social rejection, discrimination, financial-loss and stigmatization could also cause by stringent quarantine condition and necessary contact tracing policies by the health agencies (Shigimura et al. 2019, Brooks et al. 2020).

Among the frontline medical staff, increased workload, discrimination and isolation are commonly reported as their duty requires to take care of the infected individuals, to make close contacts with the cases families and most of the time they also face the public enquiring them about the current situation. Consequently, they are highly susceptible to experience fear, physical fatigue, sleep problems and emotional disturbances (Xiang et al. 2020, Kang et al. 2020). Recently, a study has been conducted which included 1,563 health professionals reported that about half of the participants $(50.7 \%)$ have symptoms of depression, $44.7 \%$ participants experienced anxiety and sleep disturbance was found in $36.1 \%$ participants (Liu et al. 2020).

Moreover, the limited availability of the knowledge about the COVID-19 pandemic and the frustrating news may also lead to fear, anxiety and uncertainty among the community (Shigimura et al. 2019, Bao et al. 2020). The general population at large scale may also suffer from boredom, irritability and disappointment under the lockdown situation (Brooks et al. 2020, Li et al. 2020)

\section{EFFECT OF COVID-19 PANDEMIC ON THE LIVES OF PATIENTS WITH MENTAL ILLNESS AND CHRONIC DISEASES}

Patients having severe mental illness (SMI) are greatly infected by SARS-CoV-2 and in February 2020, above 40 patients who were under treatment in Wuhan Mental Health Center were positive for SARS-CoV-2 and the number continue to increase as of $18^{\text {th }}$ February 323 patients having SMI were diagnosed with the disease
(Li et al. 2020). Especially those in-patients who need long term hospitalization might experience fear of high risk of cluster contagion. Moreover, out-patients having SMI are facing problems to receive maintenance treatment due to isolation measures and traffic restrictions and thus may end up with mental waning and irrepressible behaviors (e.g. agitation, self- harm and hyperactivity) (Li et al. 2020).

Similarly, patients having chronic diseases like diabetes, chronic renal-failure cardiovascular illnesses also require follow-up and proper treatment regularly. Due to COVID-19 lock down measures, these patients failed to obtain maintenance treatment. Consequently. This situation might lead to distorted physical happiness which aggravates high risk of suicidality and negative feelings.

\section{STRATEGIES FOR EMERGENCY PSYCHO- SOCIAL DISASTER INTERVENTIONS TO TACKLE PSYCHOSOCIAL CONSEQUENCES OF COVID-19 PANDEMICS}

Although the COVID-19 effects on mental health has not yet been studied analytically but it is predictable to have major effects based on current public response (Li 2020, Xiang et al. 2020). Based on this reaction National Health Commission of China on $26^{\text {th }}$ January 2020 took great steps to issue a notice specifying guidelines for emergency psycho-social disaster interventions so to lower the COVID-19 psycho-social outcomes and the psychological team consists of psychiatrists, psychological support hotlines and mental health professionals (National Health Commission of China 2020). Subsequently, on $18^{\text {th }}$ march 2020, WHO's department of Mental Health and Substance Use developed an outline describing contemplations for general and different targeted populations to support for mental health and psychosocial comfort (World Health Organization 2020), thus allowing mental health workers to help both general population and patients to understand the COVID-19 probable outcome and how to deal with new threat effectively (Hamza Shuja et al. 2020).

\section{XENOPHOBIC BEHAVIOR AND SOCIAL STIGMATIZATION}

Among the detrimental impact of pandemic infections on social and psychological aspects of life, stigmatization and xenophobia play an important role. The links between global economy, xenophobic behavior and epidemic risks has been described many times throughout the history. Xenophobia and racism also spread alongside of the spread of Corona virus. Stigmatized groups and individuals are often subjected to rejection, social avoidance, criticism, isolation, physical abuse and even elimination and refusing of employment, housing, education and healthcare services (Hamza Shuja et al. 2020). 
During the current outbreak, many people belong to Asian and Chinese lineages are suffered by social stigmatization and xenophobia with increased amount of threats during public and online interactions (World Health Organization 2020). To illustrate, Chinese population living the United Kingdom complained of being victimized to racist abuse as well the assault cases have been also reported. Similarly, the Embassy of China in Germany also reported an increase in cases against its citizens since the outbreak. In Paris, children of Asian families in some middle schools were also ostracized and mocked because of their origin. In addition to that, citizens of Wuhan in China also experienced discrimination based on their region. (Jakovljevic et al. 2020) Stigma may also occur among the individuals who are being released from quarantine. With such reaction from civilized and educated countries, third world countries like Pakistan where majority of population is deprived of basic education, this stigmatizing behavior towards suspected and confirmed cases and their families is on the rise. Therefore, it is mandatory for psychiatrists and psychologists to act unbiasedly and help educating the general public to overcome their fear and to decrease the stigmatization behavior towards the affected communities (Hamza Shuja et al. 2020).

\section{MEDICAL DISTRUST AND CONSPIRACY PHILOSOPHIES AT THE TIME OF PANDEMIC}

General sense of medical distrust is circulating among the public and masses because the health professionals and scientists failed to create a working vaccine against the SARS-CoV-2 on time which leads to enormous casualties worldwide leading to the limited use of health-care settings and poor management of health condition (Burkle et al. 2020, Ho 2020). Further, this mistrusted situation is also linked to variety of disorders and diseases which involve autism, HIV, cancer as well as disparities based on race and ethnicity (Pellowski et al. 2013).

Conspiracy theories is another important concept that comes along medical mistrust in the time of pandemic (Quinn 2018). Studies have reported various examples where false beliefs related to medical health were held by study subjects which can easily enforces and leads movements like antivaccination at the time of measles outbreak, consequently, leads to less adherence to health recommendations (Jolley \& Douglas 2014). One major example of this can be of Pakistan where many citizens do not use clinical medicines and they prefer to use herbal medicines or home remedies as well as avoiding visiting mental health professionals due to insufficient knowledge along with their beliefs in myth and the fear of being stigmatized (Keynejad 2008). Similarly, it has also been seen in various cases in the past such as polio that many Pakistani rejected polio vaccines due to many conspiracy theories regarding the vaccine (Andrade \& Hussain 2018). For this reason, the health officials along with the media should come forward and educate people about the importance of mental health issues together with the physical health during the time of a pandemic in order to maintain a myth free, fact based scientific presentation while addressing the COVID-19 important control and preventive measures (Hamza Shuja et al. 2020).

\section{LIMITED RESOURCES OF MENTAL HEALTH SERVICES AND SPECIFIC MEASURES TO OVERCOME THE PROBLEM}

Almost the entire world has been seriously affected by the Corona virus outbreak but most of the affected countries globally have limited services of mental health workers compared to the upcoming growth of its demand. To illustrate, in China, there are 2.2 number of psychiatrists per 100,000 citizens and in U.S its 11 per 100,000 inhabitants (Kirton 2020). It is clear that developing countries face various challenges in terms of financing and mental health service availability (Andrade et al. 2014), but even the developed countries like U.S also face the same problem with nearly $40 \%$ population lives in an area where there is unavailability of mental health professionals (Marr 2019). As a result, this shortage of mental health services to offer specific treatment in variety of countries represents an enormous challenge for the health officials in time of the current pandemic.

The rising demand of psychiatric services and mental health-care system might present a risk of generating public mental health crises around the globe which would be frustrating and harmful for the patients, their relatives and other mental healthcare providers. Increasing the psychiatrist numbers and improving the quality and availability of mental healthcare services will not be enough to overcome this problem. The appropriate strategy and solution to address the insufficient psychiatric services would be the use of telepsychiatry, artificial intelligence (AI) and a collection of new technologies such as internet-based computer helped mental health services and tools.

The prime example of this is the trend of using smartphones to provide the psychiatric services has started in many countries which have psychiatrist's shortage compared to the increasing demand of mental health services including China and it has provided promising results. It is also reported that every 100,000 people has less than one psychiatrist in 45 of the worlds while a smartphone is owned by every $50 \%$ of the population globally (Lovejoy 2019). Furthermore, to match the demand and to provide services for high risk groups like positive cases, health personals and quarantine people which have vulnerable psychological traits, wide use of the art tools and means of digital psychiatry should be facilitated. 


\section{ROLE OF CONSULTATION-LIAISON PSYCHIATRY AND COVID-19 PANDEMIC}

COVID-19 provides a new challenge for consultation- liaison psychiatry by offering mental health services to both patients in isolation wards and health staffs who treat them. Many psychiatrist hospitals have announced that the staff like psychiatrists can stay at home and practice telemedicine (Allen \& Mishkin 2020). Sometimes during the COVID-19 outbreak, the symptoms of Corona virus panic attacks which include chest pain, breathing difficulty, and fear of dying can be confused with respiratory distress (Onyemaechi 2020). Liaison psychiatry plays an important role in recognizing such patients thus, helps in prevent many problems. Liaison psychiatrists helps health-care professionals who are dealing with COVID-19 infected patients, and usually work within long working time and have not enough PPEs (Allen \& Mishkin 2020). An easily offered and highly proficient mental health support for all front-line health-care personals should be an important task and ethical duty of all health-care settings.

\section{CONCLUSION}

The COVID-19 pandemic has spread increased fear and frustration not only on distinct level but also on social levels and the requirement of implementing appropriate mental health safety measures together with physical health preventive measure, specifically in countries like Pakistan where the resources for mental health are very inadequate and the detection and eradication of mental health problems on time could help the patients in long term sufferings. Other policies like getting online session on mental problems from homebased can provide an easy availability to psychologists and the public for assistance and communication. Moreover, variety of long-term consequences of the mental health is expected from the outbreak, it is essential for all psychiatrists and other mental health specialists to assist their relatives and the whole public to provide well understanding of the mental issues thus, preventing mental health problems.

\section{Acknowledgements: None.}

\section{Conflict of interest: None to declare.}

\section{Contribution of individual authors:}

Study design: Samiaa Anjum, Rooh Ullah \& Rani Faryal.

Literature review: Hamid Ali Khan \& Fawad Shabir Memon.

Data collection: Yasin Ahmed \& Sadia Jabeen. First manuscript draft: Samiaa Anjum \& Rooh Ullah. Manuscript revisions: Muhammad Suleman Rana. All authors approval of the final version.

\section{References}

1. Ahmad T, Khan M, Khan FM \& Hui J: Are we ready for the new fatal Coronavirus: scenario of Pakistan? Human Vaccines \& Immunotherapeutics 2020; 16:736-8

2. Allen $N$ \& Mishkin AD: Being essential in the time of COVID-19. Psychiatric Times March 30, 2020

3. Anderson RM, Heesterbeek H, Klinkenberg D\& Hollingsworth TD: How will country-based mitigation measures influence the course of the COVID-19 epidemic. Lancet 2020; 395:931-934

4. Andrade GE \& Hussain A: Polio in Pakistan: Political, Sociological, and Epidemiological Factors. Cureus 2018; 10(10)

5. Andrade LH, Alonso J, Mneimneh Z, Wells JE, Al- Hamzawi A, Borges $G$ et al.: Barriers to mental health treatment: results from the WHO World Mental Health surveys. Psychol Med 2014; 44:1303-17

6. Bao Y, Sun Y, Meng S, Shi J \& Lu L: 2019-nCoV epidemic: address mental health care to empower society. Lancet 2020; 395:e37-8

7. Bedford J, Enria D, Giesecke J, Heymann DL, Ihekweazu C, Kobinger $G$ \& Ungchusak K: COVID-19: towards controlling of a pandemic. Lancet 2020; 395:1015-8

8. Blakey SM, Kirby AC, McClure KE, Elbogen EB, Beckham JC, Watkins LL \& Clapp JD: Posttraumatic safety behaviors: Characteristics and associations with symptom severity in two samples. Traumatology, 2019

9. Bouey J: From SARS to 2019-Coronavirus (nCoV): US China Collaborations on Pandemic Response, 2020

10. Brooks SK, Webster RK, Smith LE, Woodland L, Wessely $S$, Greenberg $N$ \& Rubin GJ: The psychological impact of quarantine and how to reduce it: rapid review of the evidence. Lancet 2020; 395:912-920

11. Burkle Jr, FM: Declining Public Health Protections within Autocratic Regimes: Impact on Global Public Health Security, Infectious Disease Outbreaks, Epidemics, and Pandemics 2020; 2:1-0

12. Cosic K, Popovic S, Sarlija M, Mijic I, Kokot M\& Kesedzic I: Multimodal physiological, voice acoustic, eye gaze and brain imaging features of stress resilience. NATOApproved Final Report of the Project NATO.MD.SFPP 984829 "Multidisciplinary Metrics for Soldier Resilience Prediction and Training", 2019

13. Gale SD, Berrett AN, Erickson LD, Brown BL \& Hedges $D W$ : Association between virus exposure and depression in US adults. Psychiatry research 2018; 261:73-79

14. Gardner PJ \& Moallef P: Psychological impact on SARS survivors: Critical review of the English language literature. Canadian Psychology/Psychologie canadienne 2015; $56: 123$

15. Hamza Shuja K, Aqeel M, Jaffar A \& Ahmed A: COVID19 pandemic and impending global mental health implications. Psychiatr Danub 2020; 32:32-5

16. Ho CS: Mental Health Strategies to Combat the Psychological Impact of COVID-19 Beyond Paranoia and Panic, 2020; 49:1-3

17. Jakovljevic M, Kurjak A, Jerkovic A, Hasanovic A \& Nikic M: Spirituality, religiosity and nationalism from the perspective of public and global mental health. Psychiatr Danub 2019; 31:382-391

18. Jakovljevic M: Empathy, sense of coherence and resilience: bridging personal, public and global mental health and conceptual synthesis. Psychiatr Danub 2018; 30:380-384 
19. Jakovljevic M: Resilience, psychiatry and religion from public and global mental health promotion. Psychiatr Danub 2017; 29:238-244

20. Johnson NP \& Mueller J: Updating the accounts: global mortality of the 1918-1920 "Spanish" influenza pandemic. Bulletin of the History of Medicine 2002; 105-115

21. Jolley D \& Douglas KM: The effects of anti-vaccine conspiracy theories on vaccination intentions. PloS one 2014; 9

22. Kaiser F: Framing risk, reducing panic during virus outbreak. 2020. Retrieved from: https://asiatimes.com/2020/ 02/framing-risk-reducingpanic-during-virus-outbreak/

23. Kang L, Li Y, Hu S, Chen M, Yang C, Yang BX et al.: The mental health of medical workers in Wuhan, China dealing with the 2019 novel coronavirus. Lancet Psychiatry 2020; 7:e14

24. Keynejad R: Barriers to seeking help. What stops ethnic minority groups in Redbridge accessing mental health services, 2008

25. Kirton D: Chinese public dial in for support as coronavirus takes mental toll. Reuters, February 13, 2020. https://www.reuters.com/article/us-china-healthmental/chinese-public-dial-in-for-support-as-coronavirustakesmental-toll-idUSKBN2070H2

26. Kuan V, Denaxas S, Gonzalez-Izquierdo A, Direk K, Bhatti $O$, Husain $S$ \& Lumbers RT: A chronological map of 308 physical and mental health conditions from 4 million individuals in the English National Health Service. The Lancet Digital Health 2019; 1:e63-e77

27. Li W, Yang Y, Liu ZH, Zhao YJ, Zhang Q, Zhang L \& Xiang YT: Progression of Mental Health Services during the COVID-19 Outbreak in China. Int J Biol Sci 2020; 16:1732-1738

28. Liu S, Yang LL, Zhang CX, Xiang YT, Liu Z, Hu S, et al.: 2019 novel coronavirus: online mental health services. Lancet Psychiatry. 2020: In press.

29. Lovejoy CA: Technology and mental health: the role of artificial intelligence. Eur Psychiatry 2019; 55:1-3

30. Marr B: The incredible ways artificial intelligence is now used in mental health. Forbes, May 3, 2019.

https://www.forbes.com/sites/bernardmarr/2019/05/03/the -incredible-ways-artificial-intelligence-is-now-usedinmental-health

31. National Health Commission of China: Principles of the emergency psychological crisis interventions for the new coronavirus pneumonia. 2020. Retrieved from: http://www.nhc.gov.cn/jkj/s3577/202001/6adc08b9665942 $53 b 2 b 791 b e 5 c 3 b 9467$

32. Onywmaechi $C$ : Redefining the role of psychiatrists in the time of COVID-19. MEDPAGE TODAY'S April 3, 2020 kevinmd-com

33. Parodi SM \& Liu VX: From Containment to Mitigation of COVID-19 in the US. JAMA 2020

34. Pellowski JA, Kalichman SC, Matthews KA \& Adler N: A pandemic of the poor: social disadvantage and the US HIV epidemic. American Psychologist 2013; 68:197

35. Person B, Sy F, Holton K, Govert B \& Liang A: Fear and stigma: the epidemic within the SARS outbreak. Emerging Infectious Diseases 2004; 10:358

Correspondence:

Rani Faryal, PhD

Department of Microbiology, Quaid-i-Azam University Islamabad, Pakistan

E-mail: ranifaryal@qau.edu.pk
36. Quinn KG, Kelly JA, DiFranceisco WJ, Tarima SS, Petroll $A E$, Sanders $C$ \& Amirkhanian YA: The health and sociocultural correlates of AIDS genocidal beliefs and medical mistrust among African American MSM. AIDS and Behavior 2018; 22:1814-1825

37. Shigemura J, Ursano RJ, Morganstein JC, Kurosawa M, Benedek DM: Public responses to the novel 2019 coronavirus (2019-nCoV) in Japan: mental health consequences and target populations. Psychiatry and clinical neurosciences 2020; 74:281

38. Shultz JM, Cooper JL, Baingana F, Oquendo MA, Espinel $Z$, Althouse BM \& Mazurik L: The role of fear-related behaviors in the 2013-2016 West Africa Ebola virus disease outbreak. Current psychiatry reports 2016; 18:104

39. Sun L, Sun Z, Wu L, Zhu Z, Zhang F, Shang $Z$ et al.: Prevalence and risk factors of acute posttraumatic stress symptoms during the COVID-19 outbreak in Wuhan, China medRxiv 2020

40. van den Heuvel L, Chishinga N, Kinyanda E, Weiss H, Patel V, Ayles $H \&$ Seedat S: Frequency and correlates of anxiety and mood disorders among TB-and HIV-infected Zambians. AIDS care 2013; 25:1527-1535

41. Wang $Y$, Wang $Y$, Chen $Y$ \& Qin Q: Unique epidemiological and clinical features of the emerging 2019 novel coronavirus pneumonia (COVID-19) implicate special control measures. Journal of Medical Virology 2020; 92:568-76

42. Williams MT, Mugno B, Franklin M \& Faber S: Symptom dimensions in obsessive-compulsive disorder: phenomenology and treatment outcomes with exposure and ritual prevention. Psychopathology 2013; 46:365-376

43. World Health Organization: Coronavirus disease (COVID19) outbreak - technical guidance - EUROPE: mental health and COVID-19. 2020. http://www.euro.who.int/en/ health-topics/health-emergencies/coronavirus-covid19/novel-coronavirus-2019-ncov-technical-guidance/ coronavirus-disease-covid-19-outbreak-technicalguidanceeurope/mental-health-and-covid-19

44. World Health Organization: Mental health and psychosocial considerations during the COVID-19 outbreak, 18 March 2020 (No. WHO/2019-nCoV/MentalHealth/2020.1)

45. Wu P, Fang Y, Guan Z, Fan B, Kong J, Yao Z \& Hoven $C W$ : The psychological impact of the SARS epidemic on hospital employees in China: exposure, risk perception, and altruistic acceptance of risk. The Canadian Journal of Psychiatry 2009; 54:302-311

46. Xiang YT, Yang $Y$, Li W, Zhang L, Zhang $Q$, Cheung $T$ \& $\mathrm{Ng} \mathrm{CH}$ : Timely mental health care for the 2019 novel coronavirus outbreak is urgently needed. Lancet Psychiatry 2020; 7:228-229

47. Yang $Y$, Peng $F$, Wang $R$, Guan K, Jiang $T, X u G$ \& Chang $C$ : The deadly coronaviruses: The 2003 SARS pandemic and the 2020 novel coronavirus epidemic in China. Journal of Autoimmunity 2020; 102434

48. Yi Y, Lagniton PN, Ye S, Li E, Xu RH, Zhong BL \& Li WT: COVID-19: what has been learned and to be learned about the novel coronavirus disease. Int J Biol Sci 2020; 16:1753-1766

49. Young JM: The Politics of Contagion, 2016 